the amplitude of the muscular contractions is practically the same, but in the absence of the caudal fin a muscular contraction on the left side of the body causes both head and tail to move simultaneously to the left of the original axis-in the presence of a caudal fin only the head moves whereas the tail remains stationary. Since the curvature of the body is the same in the two cases, it follows that the angular displacement of the head through the water is greatly reduced by the amputation of the fin. The maximum change in the direction of the fish cannot exceed the initial movement of the head, and this can only be maximal when the posterior end of the body remains undisplaced. Clearly the function of the tail fin is to enable the hind end of the body to act as a fulcrum on which the head turns. As in normal motion, the role of the caudal fin is, in the eel or dogfish, carried out by the long flexible body itself.

We have now seen that the caudal fin exerts two forces on a moving fish : (1) it tends to inhibit the transverse movements of the hind end of the body; (2) it exerts a fraction of the forward propulsive thrust. Both these forces are derived from the pressure exerted on the water at right angles to the surface of the fin. 'The 'resistant' force is the transverse component of this pressure, and the propulsive thrust is the forward component. The absolute and relative values of these forces remain to be determined.

So far, we have considered the movements of the body without reference to the actual process of contraction of the muscles. The muscle fibres of the trunk and tail all run parallel to the long axis of the body, and they are so controlled that when a fibre on one side of the body is fully contracted, its opposite neighbour on the other side of the body is fully relaxed. Further, it is clear that the fibres along one side of the body do not contract simultaneously but in sequence, beginning with those nearest to the anterior end of the body. Each group of fibres is supplied by motor nerves, and it has been suggested that a muscular wavt is the result of the passage of a nervous disturbance down one side of the spinal cord, firing off each group of fibres as it goes. It is difficult, on this view, to account for the very variable speed of transmission of the muscular waves.

There are, on the other hand, a number of facts which suggest that when the muscles (lying on one side of the base of the muscular tail) contract, their energy can be transmitted mechanically along the body of the fish just as such energy can be transmitted along the length of an elastic wire. The energy is transmitted in the form of tension by the stretched skin and muscles of the leading side of the body. If the muscles lying nearer to the tip of the tail are to be usefully employed, they must liberate their energy in phase with that of the mechanical wave. When the mechanical wave reaches any given point it first tends to store energy at that point by bending the body into a convex curve-and then this energy is afterwards liberated as the tension is released. If, therefore, the muscles at any point are to supplement this mechanical cycle, it follows that they must begin to contract at the moment when a similar shortening process is being induced by the mechanical wave. This would occur if the stimulus to contract were automatically induced by a stretching of the muscle itself. Such a proprioceptive mechanism is well defined among other vertebrate types and its existence in fish would account for many otherwise unrelated facts.

\title{
Low Auroras
}

$I^{\mathrm{T}}$ is frequently asserted $(a)$ that the aurora occasionally descends to the earth's surface so that it can be seen between the observer and relatively near terrestrial objects, and $(b)$ that not infrequently unmistakable sounds accompany auroral displays. Several writers have collected reports from residents in regions where the aurora occurs and a large mass of evidence for the reality of low auroras and sounds accompanying auroral display has been accumulated. In NATURE for March 7, 1931, Prof. S. Chapman reviewed one such collection of reports and expressed his opinion that "These letters make it difficult to deny that auroræ occur, very rarely, quite near the earth, and are sometimes accompanied by noises".

In an article which has just been published in the Quarterly Journal of the Royal Meteorological Society (vol. 59, p. 249), Dr. G. C. Simpson discusses the whole problem of low auroras and auroral sounds and comes to the conclusion that "the evidence for low auroras is extremely weak and that when one weighs that evidence against the positive information we have about the nature and position of the aurora one is justified in denying that auroras have ever been observed below a height of $80 \mathrm{~km}$." With regard to sounds, Dr. Simpson says that he is not prepared to deny the possibility that there may be some form of objective sound associated with the aurora, but he very much doubts it.

Dr. Simpson uses three main arguments against the reality of low auroras. In the first argument he points out that we now know that the chief spectroscopic line of the light of the aurora is due to a metastable state of atomic oxygen. This condition of oxygen is only possible when the pressure is very low, and trigonometrical measurements have proved that the height of the ordinary aurora is more than $80 \mathrm{~km}$., where the pressure is sufficiently low. If now an auroral streamer passes from this height to the earth's surface where the pressure is too high for atomic oxygen to exist, a second physical process must come into action, and this process, whatever it may be, would have to come into action in exactly the same pro. portion as the effect of the first process decreased, 
for the streamer must remain a streamer, the intensity of the light must not be radically changed and there must be no marked change in its colour. That there should be two such processes is very unlikely on general principles. No suggestion has been made regarding this second process except that it may be due to a high electrical field in the lower atmosphere produced by the aurora itself; but instrumental observations have shown that such high electrical fields do not accompany auroras. Further, no electrostatic field in air at atmospheric pressure can be made in the laboratory to give a glow throughout an extensive region; the highest field attainable only produces localised brush discharges or actual disruptive sparks which are not remotely like the glow of an aurora.

The second argument is based on the principles of perspective. Practically all the observers report that the low auroras look exactly like the normal auroras: they move in the same way, they appear both as streamers and as diffuse glows, they are of the same colour. No difference in breadth of streamer, rapidity of motion, intensity of light or colour is remarked upon. In fact, it is because the low aurora looks like and behaves like the high aurora that their identity is so strongly affirmed. All this is contrary to the laws of perspective. It is generally admitted that the normal aurora occurs in the upper atmosphere at a height of at least $80 \mathrm{~km}$., so that the average distance from the observer must be something like a hundred miles. If such an aurora were suddenly transferred to the neighbourhood of the observer, it certainly would not look exactly the same as it did when it was a hundred miles away. Thus the opinions so strongly held by the observers that they have seen auroras at ground level exactly like the ordinary high auroras is the strongest evidence that could possibly be given against their conclusions.

The third line of attack is to show that all the reported cases of low aurora are optical illusions. The darkness necessary for the aurora to be seen at all makes illusions easy, especially if there is a moon, for moonlight illuminates clouds and snow ridges with an intensity comparable with that of an aurora. Auroras seen between gaps in clouds or between trees when the whole landscape is dark look as though they are in front of the clouds or trees. The aurora appears in the sky simply as light masses and the observer has absolutely no criteria by which to determine the distance; but with ordinary lights their brightness and the sharpness with which they can be seen are the two factors on which judgment of distance is chiefly based. The aurora varies greatly in intensity and without exception the most brilliant auroras consist of rapidly moving, very sharply defined streamers, either in the form of curtains with clear-cut 'folds' or as long narrow shafts with relatively sharp edges. It is therefore not surprising that these auroras appear: to be much nearer than those which appear as irregular ill-defined arches and clouds. Many so-called low auroras are simply parts of haloes round the moon or are due to the illumination of fog banks or snow surfaces in bright moonlight.

In concluding his article, Dr. Simpson says that it is not possible to bring the same type of argument against the sound of an aurora as against its low position; but naturally, if the aurora is confined to the high atmosphere, sciunds are unlikely. He considers that the observed sounds are psychological, being due to the natural association of sound with the rapid movement of the streamers and the waving of the 'draperies'.

\section{Obituary}

Mr. Charles S. Carter

$\mathrm{T}$ HE death of Charles S. Carter, curator of the Museum of the Louth Naturalists', Antiquarian and Literary Society, and president of the Lincolnshire Naturalists Union in 1928 and 1929, at the age of sixty-seven, took place at Louth (Lincs) on April 14. In addition to being curator of the Museum, Mr. Carter was joint honorary secretary of the Society and conchological secretary of the Lincolnshire Naturalists Union, as well as a member of the Lincolnshire Archæological Society.

$\mathrm{Mr}$. Carter belonged to the distinguished band of self-taught amateur scientific investigators, to which local archæology and natural history in Great Britain are so deeply indebted. Not only by their individual labours, but also by the enthusiasm with which they have inspired others, they have kept alive a tradition of local interest and research, in which Great Britain stands almost, if not quite, alone.

Born in 1866 at East Torrington, Mr. Carter was educated for a short time at elementary schools, and then began work in the fields at the age of nine. He was later apprenticed to a cordwainer and worked as a cobbler for the remainder of his life. His interest in archæology and natural history began when he took up his residence in Hampshire, under the influence of Dr. S. Andrews of Basingstoke, with whom he traced the Rornan road through Pamber Forest and was a close observer of the excavation of the neighbouring Roman city of Silchester. On removing to Kent, he became associated with the late Benjamin Harrison and Dr. Lewis Ablott between the yiars 1893-1896 in the collection of eoliths. The period of his greatest activity, however, began when he returned to Louth in 1898. Among other achievements, he discovered the neolithic settlements at Tathwell and Kelstern, recorded several botanical and entomological species for the first time in the county, and found a chalk fossil, Tylopora lorea, Lang, which was new to science. Mr. Carter was a frequent contributor to the Naturalist and the Proceedings of the Lincolnshire Naturalists Union. 